\title{
Estudo qualiquantitativo do biogás produzido por substratos em biodigestores tipo batelada
}

\author{
João A. G albiatti ${ }^{1}$, Anaira D. Caramelo ${ }^{1}$, Flavia G. Silva ${ }^{1}$, Eliana A. B. Gerardi ${ }^{1} \&$ Denise A. Chiconato ${ }^{2}$
}

\section{RESUMO}

A presente pesquisa foi desenvolvida no Departamento de Engenharia Rural da FCAV/U NESP, SP, Brasil, com o objetivo de se estudar, qualiquantitativamente, o biogás produzido por 5 substratos que, após utilizados na digestão anaeróbia, foram caracterizados como: 1 - Esterco de aves de corte com cama de capim napier (EACN); 2 - Esterco de aves de corte com cama de capim napier triturado (EACNT); 3 - Esterco suíno (ES); 4 - Esterco bovino (EB) e 5 - Esterco de bovino misturado com 50\% de bagaço de cana-de-açúcar (EB50C). Dos dados levantados concluiu-se que: o substrato EACN e o ES produziram volumes maiores e menores de biogás, respectivamente, comparados com os demais; a mistura de bagaço de cana-de-açúcar no substrato EB prejudica a produção acumulada de biogás e sua qualidade; a partir dos 57 dias após o enchimento dos biodigestores todos os substratos já produziam biogás com teor de metano superior a 48\%, com exceção do substrato ES; 0 substrato triturado (EACNT) não apresentou características muito distintas do substrato não triturado (EACN); a qualidade do biogás na fase de produção máxima é semel hante para todos os substratos estudados; o biogás que mostrou maior valor de metano na sua composição foi o produzido com EB, superior em até $17,7 \%$ à produção do EACNT.

Palavras-chave: metano, qualidade, energia, esterco

\section{Q ualiquantitatve study of biogas produced by substrates in batch biodigestors}

\begin{abstract}
Aiming to study the biogas produced by 5 substrates from both quality and quantity point of view, this research was conducted at the Rural Engineering Department of FCAV/UN ESP - Brazil, State of São Paulo. The substractes that were used in the anaerobic digestion were characterized as: 1 - Slaughter fowls' manure with napier grass bed (MFN G); 2 - Slaughter fowls' manure with triturate napier grass bed (MFNGT); 3 - Suine manure (SM); 4 - Bovine manure (BM) and 5 - Bovine manure mixed with $50 \%$ of sugarcane bagasse (BM50S). From the data collected it was concluded that: the substract (MFNG) and the substract containing SM produced higher and lower volumes of biogas respectively, when compared to the others; the mixture of sugarcane bagasse in the substract containing Bovine manure damages the accumulated biogas production and its quality; 57 days after filling the biodigestors, all substrates produced biogas with a methane level higher than $48 \%$ except for the substrates containing Suine manure; the triturate substrates (MFNGT) did not present such distinct characteristics from the non-triturate substrates (MFNG); the quality of biogas at the maximum production stage was similar, for all the studied substrates; the biogas which presented higher quantity of methane in its composition was the one produced with BM, overcoming the value up to $17.7 \%$ over the MFNGT production.
\end{abstract}

Key words: methane, quality, energy, manure 


\section{INTRODUÇãO}

O desenvolvimento das civilizações, e porque não dizer, da própria História do Homem, esteve, e ainda hoje está, profundamente influenciado pela busca e descoberta de novas fontes geradoras de energia.

De acordo com os dados do Balanço Energético Nacional de 2004, as principais fontes de energia para o consumo no segmento agropecuário foram óleo diesel (58\%), lenha (26\%), energia elétrica (15\%) e outros (1\%) (Brasil, 2005). No triênio 2002-2004 dados oficiais disponíveis mostraram elevação dos preços pagos pela energia, visto que os preços do óleo diesel apresentaram aumento de $41 \%$, da lenha de $52 \%$ e da energia elétrica este aumento foi de $36 \%$, em média, no período.

Neste sentido, o desenvolvimento e a implementação de alternativas tecnológicas com vistas à geração de energia a custos reduzidos para este segmento, podem gerar impactos socioeconômicos positivos. Uma das alternativas tecnológicas mais promissoras diz respeito ao aproveitamento da biomassa para geração de energia. Conforme a literatura, a tecnologia de biodigestão anaeróbia de dejetos animais, principalmente de suínos, apresenta diversas vantagens, em que uma delas é a produção de biogás e biofertilizantes, produtos de elevado valor agregado, redução da poluição dos recursos hídricos, facilidade de implantação e operação (Leite et al., 2003; Amaral et al., 2004; Araújo et al., 2007; Factor et al., 2008; Silva \& Campos, 2008). A matéria orgânica é uma importante fonte de nutrientes para as plantas, microflora e fauna terrestre (Vilela Júnior et al., 2003; Blank et al., 2007). O biofertilizante tem sido usado na agricultura orgânica em substituição aos fertilizantes minerais (Fernandes et al., 2000; Luna et al., 2009), como forma de manter o equilíbrio nutricional de plantas e torná-las menos suscetíveis ao ataque de pragas e de patógenos.

A utilização de biodigestores contribui para a integração das atividades agropecuárias, aproveitando o esterco ao qual, normalmente, é dado pouco ou nenhum valor comercial, convertendo-o em duas bases para o desenvolvimento sustentável: em energia renovável e em fertilizante orgânico; com isto, proporciona aumentos na produção agrícola e energia para a transformação dos produtos, agregando valor, organizando a produção, aumentando a conservação e melhorando a logística de comercialização (Fernandes \& Testezlaf, 2002).

$\mathrm{O}$ baixo índice de tratamento adequado à grande quantidade de dejetos produzidos, sobretudo na suinocultura, é justamente um dos graves problemas que a intensificação da produção trouxe para o meio ambiente e para a sociedade (Belli Filho, 2001; Angonese et al., 2006). Para o esgoto doméstico a DBO (Demanda Bioquímica de Oxigênio) é de cerca de $200 \mathrm{mg} \mathrm{L}^{-1}$, a DBO dos dejetos suínos oscila entre 30.000 e $52.000 \mathrm{mg} \mathrm{L}^{-1}$, ou seja, em torno de 260 vezes superior; além disso, um suíno produz cerca de 2,5 vezes mais dejetos que um ser humano. Uma das formas de tratamento de dejetos de suínos é a utilização de sistemas anaeróbios, que possui baixo consumo energético, baixa produção de sólidos e produção de biogás (Siebenmorgent et al., 1988; Santos \& Lucas, 2004).
A avicultura é uma atividade com alto consumo energético mas tem a característica de produzir resíduos com considerável potencial energético, como a cama de frango que, ao ser processada de forma a disponibilizar essa energia, pode contribuir para um equilíbrio energético nas operações que se desenvolvem dentro do galpão. O balanço energético tem estreita relação com o balanço econômico e sua importância no setor agropecuário tem sido demonstrada em artigos, tais como a análise dos balanços energéticos e econômicos da produção de milho; refinação do óleo de amendoim; produção de silagem de milho e em granjas de postura (Campos et al., 1998; Santos \& Lucas, 2004).

O biogás possui, como composição típica, $60 \%$ de metano, 35\% de dióxido de carbono e 5\% de uma mistura de hidrogênio, nitrogênio, amônia, ácido sulfídrico, monóxido de carbono, aminas voláteis e oxigênio (Souza et al., 2005; Coelho et al., 2006). Dependendo da eficiência do processo, influenciado por fatores como carga orgânica, pressão e temperatura durante a fermentação, o biogás pode conter entre 40 e $80 \%$ de metano.

Muitas são as situações, contudo, em que não se basta ter em mãos dados tão somente referentes à quantidade de biogás produzida; é imprescindível, também, o conhecimento da qualidade deste biogás produzido, ou seja, deve-se ter a noção exata do comportamento da variação dos componentes do biogás, durante o processo fermentativo uma vez que, com base nesses dados é que se pode constatar e caracterizar sua variação na fermentação e poder sugerir controle da qualidade do gás a ser purificado e armazenado.

Em função do exposto se propõe, neste trabalho, analisar a qualidade e a quantidade do biogás produzido por 5 substratos em biodigestores tipo batelada.

\section{MATERIAL E MÉTODOS}

O experimento foi desenvolvido no Departamento de Engenharia Rural da Faculdade de Ciências Agrárias e Veterinárias, pertencente à UNESP, localizada em Jaboticabal, SP, a uma latitude de $21^{\circ} 15^{\prime} 22^{\prime \prime}$, longitude de $48^{\circ} 18^{\prime} 58^{\prime \prime}$ e altitude de $575 \mathrm{~m}$.

Utilizou-se, para condução e desenvolvimento da pesquisa, uma bateria de 20 unidades de biodigestores, tipo batela$\mathrm{da}$, com capacidade total de $70 \mathrm{~L}$ cada uma; os biodigestores se constituíram, basicamente, de dois cilindros circulares retos, um dos quais se encontrava implantado no interior do outro, de tal forma que o espaço existente entre a parede externa do cilindro interior e a parede interna do cilindro exterior, abrigava um volume de água denominado "selo d' água", que atingia a profundidade de $50 \mathrm{~cm}$.

Uma campânula flutuante emborcada no "selo d'água" propiciava as condições anaeróbicas através das quais se desenvolveu o processo de fermentação, além de reter o gás produzido.

Os substratos utilizados foram: 1 - Esterco de aves de corte com cama de capim napier (EACN); 2 - Esterco de aves de corte com cama de capim napier triturado (EACNT); 3 - Ester- 
co suíno (ES); 4 - Esterco bovino (EB) e 5 - Esterco de bovino misturado com 50\% de bagaço de cana-de-açúcar (EB50C).

Após o recolhimento dos substratos fez-se a caracterização quanto à sua granulometria, mediante o uso de um equipamento denominado Granutest, que possui diversas peneiras com crivos de diferentes diâmetros.

De acordo com esses dados, os estercos foram analisados em relação aos seus aspectos; o esterco de aves de corte com cama de capim napier (EACN) e o esterco de aves de corte com cama de capim napier triturado (EACNT) foram obtidos de aves da linhagem HUBBARD com 58 dias; a ração utilizada possuía, como ingredientes, milho, soja, farinha de osso, sal iodado e o suplemento vitamínico. O esterco de bovino misturado com 50\% de bagaço de cana-de-açúcar (EB50C) teve o bagacilho coletado em usina de açúcar e álcool situada próximo ao local onde se desenvolveu o experimento. Os dados granulométricos de EACN, EACNT e EB50C estão apresentados na Tabela 1.

Tabela 1. Dados do aspecto granulométrico dos substratos EACN, EACNT e EB50C

\begin{tabular}{cccc}
\hline $\mathbf{N}^{0}$ Peneira & Peso (\%) EACN & Peso (\%) EACNT & Peso (\%) EB50C \\
5 & 41,40 & 6,17 & 42,18 \\
10 & 12,75 & 16,28 & 18,93 \\
16 & 18,51 & 26,50 & 12,22 \\
32 & 13,22 & 26,70 & 14,27 \\
48 & 5,62 & 7,53 & 5,78 \\
Fundo & 8,50 & 16,82 & 6,62 \\
\hline
\end{tabular}

Em seguida, analisou-se o esterco suíno (ES), proveniente de animais da raça Landrace, com idade entre 5 a 6 meses; a alimentação fornecida foi formulada à base de milho, sal comum, farinha de osso, map e suplemento protéico, para o qual não foi feita caracterização granulométrica, sendo colocado fresco no biodigestor; o mesmo ocorreu com o esterco de bovino (EB), quando não se realizou a caracterização granulométrica; tal esterco foi originado de gado leiteiro, com idade variando entre 4 a 5 anos; a ração fornecida aos animais se constituía de farelo de trigo, milho, farinha de osso e sal comum.

Dois dias antes do abastecimento se retiraram 3 amostras representativas de cada esterco para estimativa da porcentagem média de sólidos totais; essas amostras foram acondicionadas em recipientes previamente tratados e pesadas e posteriormente levadas à estufa com circulação forçada de ar, a temperatura de $80^{\circ} \mathrm{C}$, até atingirem peso constante e, em seguida, pesadas; após os cálculos as biomassas foram levadas próximo à bateria de biodigestores para a elaboração das misturas previstas. Utilizaram-se um recipiente metálico previamente tratado, uma balança, água de poço artesiano e uma colher de madeira para homogeneizar a mistura. O recipiente era colocado na balança em que se punham, também, os substratos e, logo após, a água, até atingir os níveis ideais para o processo de biodigestão; mexia-se muito bem, até atingir bom estado de fragmentação e imediatamente a mistura era colocada no biodigestor.
Realizado o enchimento dos biodigestores, o biogás produzido era medido constantemente multiplicando-se o deslocamento vertical diário da campânula por sua área de secção interna e as leituras se processaram durante 250 dias.

Para realização da coleta do biogás confeccionou-se recipiente utilizando-se um frasco de vidro com capacidade de $500 \mathrm{~mL}$, o qual era tapado com tampa de borracha, em que se deixaram duas aberturas nas quais foram introduzidos 2 tubos de vidro que continham, em suas extremidades, tubos de látex flexíveis para a vedação das saídas com o auxílio de presilhas metálicas. Neste frasco se efetuou um vácuo para eliminar os gases contaminantes provenientes da atmosfera; depois, o recipiente foi levado até o local da coleta do biogás e, através de manômetro de coluna d'água, coletou-se a amostra gasosa a uma pressão de $16 \mathrm{~cm}$ de coluna de água; efetuada a coleta, a amostra de biogás foi levada ao laboratório central da FCAV/UNESP para a análise qualiquantitativa dos seus componentes, através de cromatografia em fase gasosa.

O biogás contido no recipiente amostrador era retido e injetado no cromatógrafo com seringas, para registro, em gráficos, dos impulsos gerados; a partir dos dados obtidos, elaboraram-se tabelas representativas dos valores contidos nas amostras para se obter informações específicas de cada tipo de substrato utilizado no experimento e quais as características positivas e negativas de cada um, facilitando seu emprego nas mais diversas atividades.

\section{RESULTADOS E DISCUSSÃO}

Os resultados dos experimentos apresentaram primeiro, dados de produção de biogás na forma de acúmulos quinzenais e totais, como se observa na Tabela 2; desses dados se constata que o substrato (EACN), ou seja, esterco de aves de corte com cama de capim napier, teve produção acumulada superior enquanto o esterco de suíno (ES) apresentou produção inferior à dos demais, no final do período estudado; ressalta-se que aos 250 dias este apresentava produção quinzenal superior à dos demais.

De maneira geral, o período de produção máxima dos substratos se iniciou aos 45 dias, começando a decair a partir do $105^{\circ}$ dia após a colocação dos substratos nos biodigestores, com exceção do esterco suíno (ES) que teve sua produção máxima no intervalo dos 90 aos 135 dias.

Quando se comparou a produção do substrato sem triturar com o triturado, aos 250 dias de produção acumulada, notou-se que o (EACN) apresentou $1328,5 \mathrm{~m}^{3}$ e o (EACNT) valor de $1252,0 \mathrm{~m}^{3}$ havendo, portanto, uma pequena superioridade na produção de biogás por parte do sem triturar, ou seja, 76,5 m³ no entanto, sua produção máxima se iniciou e terminou 15 dias antes, dos 45 aos 90 dias.

Os materiais com esterco de bovino indicaram produções acumuladas de 900,4 $\mathrm{m}^{3}$ quando sem bagaço de cana e de $679,2 \mathrm{~m}^{3}$ com $50 \%$ de bagaço seco de cana-de-açúcar, mostrando menor produção de biogás; referidos substratos tiveram produções máximas entre 45 e 120 dias após o enchimento dos biodigestores. 
Tabela 2. Produção média de Biogás $\left(\mathrm{m}^{3}\right)$, Acumulada $(A)$ e $Q$ uinzenal $(\mathrm{Q})$, em função dos substratos utilizados

\begin{tabular}{|c|c|c|c|c|c|c|c|c|c|c|c|c|c|c|c|c|c|}
\hline \multirow[b]{2}{*}{ Subs. } & \multirow[b]{2}{*}{ Prod. } & \multicolumn{16}{|c|}{ Dias após enchimento dos biodigestores } \\
\hline & & 15 & 30 & 45 & 60 & 75 & 90 & 105 & 120 & 135 & 150 & 165 & 180 & 195 & 210 & 230 & 250 \\
\hline \multirow{2}{*}{ EACN } & Q & 26,9 & 25,4 & 467,6 & 396,3 & 216,5 & 99,7 & 46,1 & 26,7 & 2,8 & 3,0 & 4,5 & 5,5 & 2,5 & 3,0 & 2,0 & 0,0 \\
\hline & $A$ & 26,9 & 52,3 & 519,9 & 916,2 & 1132,7 & 1232,4 & 1278,5 & 1305,2 & 1308,0 & 1311,0 & 1311,0 & 1321,0 & 1323,5 & 1326,5 & 1328,5 & 1328,5 \\
\hline \multirow{2}{*}{ EACNT } & $Q$ & 24,5 & 5,2 & 26,1 & 310,5 & 134,4 & 134,4 & 142,3 & 53,3 & 9,0 & 30,0 & 30,0 & 13,0 & 6,0 & 4,0 & 5,5 & 3,5 \\
\hline & A & 24,5 & 29,7 & 55,8 & 366,3 & 969,4 & 969,4 & 1111,7 & 1165,0 & 1174,0 & 1204,0 & 1204,0 & 1233,0 & 1239,0 & 1243,0 & 1248,5 & 1252,0 \\
\hline \multirow{2}{*}{ ES } & $Q$ & 4,7 & 3,7 & $-0,6$ & 0,3 & 58,2 & 56,2 & 43,7 & 91,9 & 49,0 & 48,0 & 48,0 & 11,5 & 5,5 & 7,0 & 11,5 & 13,0 \\
\hline & A & 4,7 & 8,4 & 7,8 & 8,1 & 75,8 & 75,8 & 119,5 & 211,4 & 260,4 & 308,4 & 308,4 & 344,4 & 349,9 & 356,9 & 368,4 & 381,4 \\
\hline \multirow{2}{*}{ EB } & $Q$ & 4,2 & 37,0 & 252,2 & 178,5 & 95,4 & 95,4 & 70,4 & 45,7 & 9,9 & 19,0 & 19,0 & 10,0 & 7,5 & 7,0 & 7,0 & 2,0 \\
\hline & A & 4,2 & 41,2 & 293,4 & 471,9 & 720,4 & 720,4 & 790,8 & 836,5 & 846,4 & 865,4 & 865,4 & 876,9 & 884,4 & 891,4 & 898,4 & 900,4 \\
\hline \multirow{2}{*}{ EB50C } & $Q$ & $-0,3$ & 20,4 & 137,4 & 78,9 & 135,1 & 135,1 & 72,9 & 40,7 & 8,2 & 18,0 & 18,0 & 18,0 & 15,0 & 13,0 & 13,0 & 4,0 \\
\hline & $A$ & $-0,3$ & 20,1 & 157,5 & 236,4 & 465,4 & 465,4 & 538,3 & 579,0 & 327,2 & 605,2 & 605,2 & 634,2 & 649,2 & 662,2 & 675,2 & 679,2 \\
\hline
\end{tabular}

O valor calorífico do biogás é a função da sua qualidade sendo diretamente proporcional ao aumento da porcentagem de metano na mistura, Sathianathan (1975). O poder calorífico do biogás é variável, sendo aproximadamente de 22.500 a $25.000 \mathrm{~kJ} \mathrm{~m}^{-3}$, assumindo o metano com cerca de $35.800 \mathrm{~kJ} \mathrm{~m}^{-3}$, significando um aproveitamento de 6,25 a $10 \mathrm{kWh} \mathrm{m}^{-3}$ (Jordão \& Pessoa, 1995); sua potencialidade é demonstrada quando tratado (remoção de $\mathrm{CO}_{2}$ ), pois seu poder calorífico pode chegar a $60 \%$ do poder calorífico do gás natural e, assim sendo, deve-se analisar os substratos produtores de biogás não só pelo volume produzido de biogás mas também por sua qualidade.

Ross et al. (1996) citam que o metano puro nas condições normais de temperatura e pressão, possui poder calorífico de aproximadamente $33.980 \mathrm{~kJ} \mathrm{~m}^{-3}$; o biogás, com $65 \%$ de metano, tem poder calorífico de mais ou menos $22.353 \mathrm{~kJ} \mathrm{~m}^{-3}$, haja vista que apenas o metano irá queimar. Ross et al. (1996) ainda indicam que $1 \mathrm{~m}^{3}$ de biogás com $65 \%$ de metano equivale a $0,6 \mathrm{~m}^{3}$ de gás natural; $0,882 \mathrm{~L}$ de propano; $0,789 \mathrm{~L}$ de butano; 0,628 L de gasolina; 0,575 L de óleo combustível e 0,455 $\mathrm{kg}$ de carvão betuminoso ou 1,602 $\mathrm{kg}$ de lenha seca.

Tem-se, na Tabela 3, os dados de teor de metano no biogás determinados quinzenalmente, durante o desenvolvimento do experimento; dentre os dados se verifica que aos 57 dias após o enchimento dos biodigestores o gás produzido possuía teores de metano superiores a $48 \%$, com exceção apenas do produzido pelo substrato ES que, neste dia, estava com 16,8\% de metano; a partir dos 99 dias após o enchimento dos biodigestores, todos os substratos produziram biogás com teores de metano aproximadamente $70 \%$.

Segundo Konzen (1983), os dejetos de suínos possuem bom potencial energético na produção de biogás, visto que mais de $70 \%$ dos seus sólidos totais são constituídos de sólidos voláteis, componentes essenciais do substrato para o processo de biodigestão anaeróbia, porém o aspecto fundamental para a produção efetiva de biogás é de que o grupo de micro-organismos encontre o ambiente favorável ao seu desenvolvimento, sendo a temperatura um dos principais parâmetros dos quais as bactérias dependem, em especial as metanogênicas Tchobanoglous, estabelecendo a qualidade e a quantidade do biogás produzido.

Verifica-se, de acordo com a Tabela 3 e se comparando os dados de porcentagem de metano no biogás produzido pelos substratos, que o tratamento contendo esterco de suíno apresentou concentrações inferiores de metano no biogás em relação aos demais tratamentos, até os 99 dias após o enchimento dos biodigestores e, desse dia em diante, passou a ter porcentagens de $\mathrm{CH}_{4}$ semelhantes às dos outros, ou seja, aproximadamente de $70 \%$ do biogás.

Ao se observar o tratamento contendo material triturado, nota-se comportamento oscilatório em relação ao material não triturado, apresentando maiores quantidades de metano no biogás apenas aos $85(57,01 \%), 99(76,23 \%), 169(75,48 \%)$ e $183(79,56 \%)$ dias; o tratamento do substrato não triturado indicou porcentagem maior de metano no biogás, superandoo aos 217 dias, sendo que já na primeira análise, ou seja, no $43^{\circ}$ dia, a diferença já se mostrou acentuada, atingindo $76,52 \%$; assim, a quantidade de metano no biogás produzido pelo substrato de esterco de aves de corte com cama de capim napier $(\mathrm{EACN})$ sem triturar, mostrou-se superior à do triturado; o Esterco de Bovino (EB), foi o de maior concentração total de metano no biogás até 99 dias após enchimento do biodigestor superado, desse dia em diante, pelo EACN e ES.

Tabela 3. Teor médio de metano (\%) no biogás em função dos substratos

\begin{tabular}{|c|c|c|c|c|c|c|c|c|c|c|c|c|}
\hline \multirow[b]{2}{*}{ Subs. } & \multicolumn{12}{|c|}{ Dias após 0 enchimento } \\
\hline & 43 & 57 & 71 & 85 & 99 & 113 & 127 & 141 & 155 & 169 & 183 & 217 \\
\hline EACN & 44,59 & 48,35 & 60,58 & 52,93 & 65,24 & 82,47 & 85,03 & 85,84 & 81,75 & 74,00 & 71,76 & 78,96 \\
\hline EACNT & 25,26 & 48,35 & 55,45 & 57,01 & 76,23 & 75,78 & 72,57 & 73,26 & 73,50 & 75,48 & 79,56 & - \\
\hline ES & 10,40 & 16,80 & 22,37 & 48,35 & 67,43 & 78,01 & 81,36 & 82,88 & 81,00 & 79,18 & 81,12 & 84,00 \\
\hline EB & 54,25 & 59,44 & 61,04 & 53,95 & 76,23 & 70,60 & 77,70 & 78,44 & 75,00 & 74,00 & 76,44 & 81,48 \\
\hline EB50C & 49,05 & 51,91 & 54,05 & 50,90 & 71,10 & 77,27 & 83,56 & 84,36 & 78,00 & 72,52 & 74,10 & 84,84 \\
\hline
\end{tabular}

$\mathrm{EACN} \Rightarrow \mathrm{Y}=-0,0027 \mathrm{X}^{2}+0,8822 \mathrm{X}+8,8116 / \mathrm{R}^{2}=0,7992 ; \mathrm{EACNT} \Rightarrow \mathrm{Y}=-0,0081 \mathrm{X}^{2}+2,0695 \mathrm{X}-50,452 / \mathrm{R}^{2}=0,8249 ; \mathrm{ES}=>\mathrm{Y}=-0,0048 \mathrm{X}^{2}$

$+1,6667 X-58,481 / R^{2}=0,9400 ; E B \Rightarrow Y=-0,001 X^{2}+0,3975 X+38,258 / R^{2}=0,7663 ; E B 50 C=Y=-0,0017 X^{2}+0,6458 X+20,704 / R^{2}$ $=0,7715$ 
De acordo com a mesma tabela, as equações de regressão representam, em função da época, a evolução na qualidade do biogás representado pelo teor de metano nos substratos utilizados, tendo o ES a medida de grau de ajuste em $\mathrm{R}^{2} 0,9400$, o que demonstra o melhor ajuste dessa equação para o referido substrato porém o EB50C foi o que apresentou menor valor de ajuste, sendo estabelecido em $\mathrm{R}^{2}=$ 0,7715 , o que indica menor precisão em relação aos demais substratos testados.

Analisando-se os dados da Tabela 4, nota-se que os teores de $\mathrm{CO}_{2}$ são maiores no início da fermentação anaeróbia em todos os substratos estudados, ocorrendo os picos máximos até os 71 dias de fermentação anaeróbia e dos 183 dias em diante este elemento apareceu em porcentagens menores. Espécies metanogênicas de bactérias, através da descarboxilação do acetato ou da redução do dióxido de carbono pelo hidrogênio, produzem o metano, a forma gasosa mais reduzida do carbono na natureza (Vazzoler, 1993). No início da fermentação anaeróbia ainda não há seleção de micro-organismos, sendo as bactérias metanogênicas ainda pouco eficientes ou em número menor que as produtoras de $\mathrm{CO}_{2}$, concordante com Sathianathan (1975), além do que existe oxigênio no meio, em teores significativos para o processo.

De acordo com as regressões apresentadas na Tabela acima, observa-se que a equação que melhor se ajustou ao gráfico foi do substrato EACN, com $\mathrm{R}^{2}$ 0,8920, indicando que possui maior grau de ajuste da regressão estimada, sendo que o oposto se observa no EB50C, com um R²0,0620.

Verifica-se, na mesma Tabela, que o teor de gás carbônico no substrato composto por esterco de aves de corte com cama de capim napier (EACN), foi superior ao substrato análogo triturado (EACNT) até os 71 dias de fermentação; no entanto, a partir do $85^{\circ}$ dia de fermentação este último teve menores teores de $\mathrm{CO}_{2}$ até o final da fermentação; no EB e EB50C não houve um material que condicionasse maiores ou meno- res porcentagens de $\mathrm{CO}_{2}$ para este ou aquele substrato, visto que, às vezes, um biogás continha teores de $\mathrm{CO}_{2}$ maiores que os demais e ora continha teores inferiores que os demais; entretanto, ao se observar os valores totais, notou-se que o substrato EB50C produziu, em geral, maiores valores de $\mathrm{CO}_{2}$ em relação aos demais, especialmente a partir dos 141 dias de fermentação; o substrato EACN produziu pequena porcentagem de $\mathrm{CO}_{2}$ ao final dos 169 dias, embora tenha tido a maior taxa aos 43 dias mas o ES apresentou a menor porcentagem, comparado aos demais substratos.

O biogás produzido pelos substratos testados mostrou altos teores de oxigênio, como se pode observar na Tabela 5.

Os dados da Tabela 5 demonstram que as porcentagens de $\mathrm{O}_{2}$ se mantiveram entre 1,0 e $1,5 \%$ dos 155 dias em diante. Os tratamentos testados produziram biogás com teores de $\mathrm{O}_{2}$ bem semelhantes em cada amostragem e tenderam a diminuir os valores com o passar do tempo; aos 43 dias notou-se que o substrato EB50C apresentou maior índice de oxigênio no biogás $(2,56 \%)$ e o EACNT o menor $(2,16 \%)$, porém a diferença foi de apenas $0,40 \%$. Com o decorrer do tempo todos os substratos apresentaram queda nas porcentagens, embora somente o EACNT tenha obtido $0 \%$ aos 217 dias, depois de instalado o experimento.

De acordo com as análises de regressão, a equação que melhor se ajustou à curva, foi a do substrato EACNT $\left(\mathrm{R}^{2} 0,8290\right)$, seguida pelo EB50C $\left(\mathrm{R}^{2}=0,7490\right), \mathrm{EACN}\left(\mathrm{R}^{2}=\right.$ $0,6040), \mathrm{EB}\left(\mathrm{R}^{2}=0,4210\right)$ e $\mathrm{ES}\left(\mathrm{R}^{2}=0,2300\right)$.

\section{CONCLUSÕES}

1. Os maiores e menores volumes de biogás foram obtidos com o substrato composto de esterco de aves de corte com cama de capim napier (EACN) e esterco de suíno (ES), respectivamente.

Tabela 4. Teor médio de gás carbônico (\%) no biogás em função dos substratos utilizados

\begin{tabular}{|c|c|c|c|c|c|c|c|c|c|c|c|c|}
\hline \multirow[b]{2}{*}{ Subs. } & \multicolumn{12}{|c|}{ Dias após 0 enchimento } \\
\hline & 43 & 57 & 71 & 85 & 99 & 113 & 127 & 141 & 155 & 169 & 183 & 217 \\
\hline EACN & 30,62 & 21,00 & 28,00 & 7,00 & 10,50 & 7,00 & 3,50 & 1,05 & 0,87 & 0,00 & 0,00 & 0,00 \\
\hline EACNT & 22,96 & 14,00 & 16,80 & 14,00 & 21,00 & 17,50 & 8,75 & 7,00 & 8,75 & 11,66 & 3,00 & 0,00 \\
\hline ES & 7,0 & 11,20 & 14,00 & 8,75 & 14,00 & 17,50 & 7,00 & 7,00 & 8,75 & 5,83 & 5,00 & 0,00 \\
\hline EB & 16,41 & 28,00 & 17,50 & 17,50 & 21,00 & 7,00 & 11,37 & 13,12 & 13,12 & 11,66 & 0,00 & 0,00 \\
\hline EB50C & 16,41 & 21,00 & 16,80 & 17,50 & 21,00 & 14,00 & 7,00 & 10,50 & 35,00 & 17,49 & 10,00 & 10,00 \\
\hline
\end{tabular}

$\mathrm{EACN}=>\mathrm{Y}=0,001 \mathrm{X}^{2}-0,587 \mathrm{X}+52,55 / \mathrm{R}^{2}=0,8920 ; \mathrm{EACNT} \Rightarrow \mathrm{Y}=-0,000 \mathrm{X}^{2}-0,038 \mathrm{X}+21,80 / \mathrm{R}^{2}=0,7390 ; \mathrm{ES}=>\mathrm{Y}=-0,000 \mathrm{X}^{2}+0,163 \mathrm{X}$ $+4,005 / R^{2}=0,6340 ; E B \Rightarrow Y=-0,000 X^{2}-0,030 X+23,13 / R^{2}=0,6740 ; E B 50 C \Rightarrow Y=-0,000 X^{2}+0,057 X+15,40 / R^{2}=0,0620$

Tabela 5. Teor médio de oxigênio (\%) no biogás, em função dos substratos utilizados

\begin{tabular}{|c|c|c|c|c|c|c|c|c|c|c|c|c|}
\hline \multirow[b]{2}{*}{ Subs. } & \multicolumn{12}{|c|}{ Dias após o enchimento } \\
\hline & 43 & 57 & 71 & 85 & 99 & 113 & 127 & 141 & 155 & 169 & 183 & 217 \\
\hline EACN & 2,49 & 2,31 & 1,92 & 3,18 & 2,31 & 1,75 & 1,40 & 1,33 & 1,00 & 1,00 & 1,14 & 1,50 \\
\hline EACNT & 2,16 & 2,64 & 2,31 & 2,27 & 2,00 & 1,50 & 1,75 & 1,99 & 1,00 & 1,25 & 1,43 & 0,00 \\
\hline ES & 2,33 & 2,00 & 0,77 & 2,73 & 2,00 & 1,50 & 1,50 & 1,99 & 1,50 & 1,50 & 1,14 & 1,25 \\
\hline$E B$ & 2,33 & 0,99 & 2,31 & 2,73 & 2,00 & 1,75 & 150 & 1,99 & 1,00 & 1,00 & 1,14 & 1,00 \\
\hline EB50C & 2,56 & 2,00 & 2,31 & 1,82 & 2,00 & 1,75 & 1,50 & 1,99 & 1,20 & 1,00 & 1,14 & 1,50 \\
\hline
\end{tabular}

$\mathrm{EACN}=>\mathrm{Y}=5 \mathrm{E}-05 \mathrm{X}^{2}-0,022 \mathrm{X}+3,634 / \mathrm{R}^{2}=0,6040 ; \mathrm{EACNT}=>\mathrm{Y}=-6 \mathrm{E}-05 \mathrm{X}^{2}-0,003 \mathrm{X}+2,298 / \mathrm{R}^{2}=0,8290 ; \mathrm{ES}=>\mathrm{Y}=-6 \mathrm{E}-06 \mathrm{X}^{2}-0,003 \mathrm{X}$ $+2,193 / R^{2}=0,2300 ; E B \Rightarrow Y=-3 E-05 X^{2}+0,001 X+2,100 / R^{2}=0,4210 ; E B 50 C \Rightarrow Y=5 E-06 X^{2}+0,011 X+15,40 / R^{2}=0,7490$ 
2. A mistura de bagaço de cana-de-açúcar no substrato contendo Esterco de Bovino prejudica a produção acumulada de biogás e sua qualidade.

3. A partir dos 57 dias após o enchimento dos biodigestores, todos os substratos já produziam biogás com teor de metano superior a $48 \%$, com exceção do substrato contendo Esterco de Suíno.

4. O esterco triturado não apresentou características muito distintas do esterco não triturado neste tipo de substrato (EACN).

5. A qualidade do biogás na fase de produção máxima é semelhante para todos os substratos em questão.

6. O biogás que apresentou maior valor de metano na sua composição, foi o produzido com esterco bovino (EB) superando, em até $17,7 \%$, a produção com esterco de aves de corte com cama de capim napier triturado.

\section{LITERATURA CITADA}

Amaral, C. M. C.; Amaral, L. A.; Lucas Júnior, G.; Nascimento, A. A.; Ferreira, D. S.; Machado, M. R. F. Biodigestão anaeróbia de dejetos de bovinos leiteiros submetidos a diferentes tempos de retenção hidráulica. Ciência Rural, v.34, n.6, p.1897-1902, 2004.

Angonese, A. R.; Campos, A. T.; Zacarkim, C. E.; Matsuo, M. S.; Cunha, F. Eficiência energética de sistema de produção de suínos com tratamento dos resíduos em biodigestor. Revista Brasileira de Engenharia Agrícola e Ambiental, v.10, n.3, p.745-750, 2006.

Araújo, E. N.; Oliveira, A. P.; Cavalcante, L. F.; Pereira, W. E.; Brito, N. M.; Neves, C. M. L.; Silva, E. E. Produção do pimentão adubado com esterco bovino e biofertilizante. Revista Brasileira de Engenharia Agrícola e Ambiental, v.11, n.5, p.466-470, 2007.

Belli Filho, P.; Castilhos, A. B.; Costa, R. H. R.; Soares, S. R.; Perdomo, C. C. Tecnologias para o tratamento de dejetos de suínos. Revista Brasileira de Engenharia Agrícola e Ambiental, v.5, n.1, p.166-170, 2001.

Blank, A. F.; Blank, M. F. A.; Amancio, V. F.; Mendonça, M. C.; Santana Filho, L. G. M. Densidades de plantio e doses de biofertilizante na produção de capim-limão. Horticultura Brasileira, v.25, n.3, p.343-349, 2007.

Brasil. Ministério das Minas e Energia. Balanço energético nacional. 2005. <http://www.mme.gov.br>. 02 Jun. 2008.

Campos, A. T.; Ferreira, W. A.; Yamaguchi, L. C. T.; Resende, H.; Alemida, F. M. Balanço econômico e energético na produção de silagem de milho em sistema intensivo de produção de leite. Engenharia Rural, v.9, n.1, p.10-20, 1998.

Coelho, S. T.; Velásquez, S. M. S. G.; Silva, O. C.; Pecora, V.; Abreu, F. C. Geração de energia elétrica a partir do biogás proveniente do tratamento de esgoto. In: Congresso Brasileiro de Energia, 11, 2006, Rio de Janeiro. Anais... Rio de Janeiro: PIPGE, 2006. 5p.
Factor T. L.; Araújo, J. A. C.; Vilela Júnior, L. V. E. Produção de pimentão em substratos e fertirrigação com efluente de biodigestor. Revista Brasileira de Engenharia Agrícola e Ambiental, v.12, n.2, p.143-149, 2008.

Fernandes, A. L. T.; Testezlaf, R. Fertirrigação na cultira do melão em ambiente protegido, utilizando-se fertilizantes organominerais e químicos. Revista Brasileira de Engenharia Agrícola e Ambiental, v.6, n.1, p.45-50, 2002.

Fernandes, M. C. A.; Leal, M. A. A.; Ribeiro, R. L. D.; Araújo, M. L.; Almeida, D. L. Cultivo protegido do tomateiro sob manejo orgânico. A Lavoura, v.103, n.634, p.44-45, 2000.

Jordão, E. P.; Pessoa, C. A. Tratamento de esgotos domésticos. 3.ed. Rio de Janeiro: ABES, 1995. 720p.

Konzen, E. A. Manejo e utilização de dejetos de suínos. Concódia: Embrapa CNPSA, 1983, 32p.

Leite, V. D.; Sousa, J. T.; Prasad, S.; Lopes, W. S.; Athayde Júnior, G. B.; Dantas, A. M. M. Tratamento de resíduos sólidos de centrais de abastecimento e feiras livres em reator anaeróbio de batelada. Revista Brasileira de Engenharia Agrícola e Ambiental, v.7, n.2, p.318-322, 2003.

Luna, M. L. D.; Leite, V. D.; Lopes, W. S.; Sousa, J. T.; Silva, S. A. Tratamento anaeróbio de resíduos orgânicos com baixa concentração de sólidos. Engenharia Agrícola, v.29, n.1, p.113121, 2009.

Ross, C. C.; Drake, T. J.; Walsh, J. L. Handbook of biogas utilization. 2.ed. Atlanta: U.S. Department of Energy, 1996. 2p.

Santos, T. M. B.; Lucas J. J. Balanço energético em galpão de frangos de corte. Engenharia Agrícola, v.24, n.1, p.25-36, 2004.

Sathianathan, M. A. Biogas achievements challenges. New Delhi: Association of Voluntary Agencies for Rural Development, 1975. 192p.

Siebenmorgent, T. J.; Schulte, D. D.; Ballard, J. L. Integration of a cogeneration system into a swine operation: 1 . Model development and system description. Transactions of the ASAE, v.31, n.5, p.1556-1565, 1988.

Silva, T. N.; Campos, L. M. S. Avaliação da produção e qualidade do gás de aterro para energia no aterro sanitário dos Bandeirantes - SP. Engenharia Sanitária e Ambiental, v.13, n.1, p.88-96, 2008.

Souza, C. F.; Lucas J. J.; Ferreira W. P. M. Biodigestão anaeróbia de dejetos de suínos sob efeito de três temperaturas e dois níveis de agitação do substrato: Considerações sobre a partida. Engenharia Agrícola, v.25, n.2, p.530-539, 2005.

Vazoller, R. F. Características e interações microbianas nos processos de tratamento biológico aeróbio e anaeróbio. In: Curso de Processos Biológicos de Tratamento de Resíduos, 2, 1993, São Paulo. Curso... São Paulo: Instituto de Pesquisas Tecnológicas do Estado de São Paulo, 1993. p.18.

Vilela Júnior, L. V. E. V.; Araújo J. A. C.; Factor T. L. Estudo da utilização do efluente de biodigestor no cultivo hidropônico do meloeiro. Revista Brasileira de Engenharia Agrícola e Ambiental, v.7, n.1, p.72-79, 2003. 